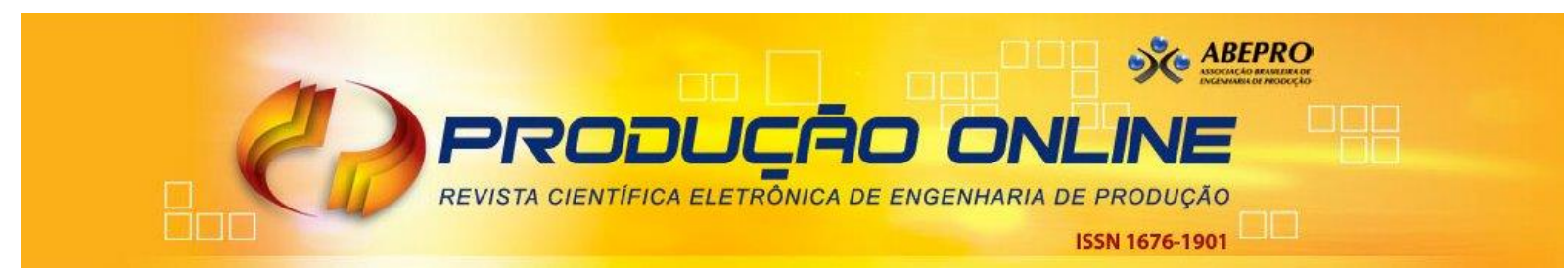

\title{
APLICAÇÃO DO DESDOBRAMENTO DA FUNÇÃO QUALIDADE EM SERVIÇOS: UMA ANÁLISE DA LITERATURA
}

\section{QUALITY FUNCTION DEPLOYMENT (QFD) APPLICATION IN SERVICES: A LITERATURE ANALYSIS}

\author{
Victor Hugo Aurélio de Souza* E-mail: vhsouza@gmail.com \\ Paulo Augusto Cauchick-Miguel* E-mail: paulo.cauchick@ufsc.br \\ *Universidade Federal de Santa Catarina (UFSC), Florianópolis, SC
}

Resumo: A crescente competição tem obrigado as empresas a proverem serviços inovadores de modo a exceder as expectativas dos clientes garantindo sua competitividade no mercado. Assim, compreender quais são as necessidades dos clientes e como atendê-las é algo imperativo para as organizações. O desdobramento da função qualidade (quality function deployment - QFD) é um método que busca atingir este propósito. Neste âmbito, o presente trabalho tem por objetivo demonstrar as aplicações do QFD no contexto de serviços por meio de uma revisão bibliográfica. Para atender esse objetivo, um processo estruturado de busca e organização bibliográfica foi aplicado para a seleção e análise de um portfólio resultante de 25 artigos estritamente ligados ao tema central do QFD aplicado a serviços. Os resultados obtidos mostram que o emprego do QFD é preponderantemente restrito a primeira matriz e ao levantamento das necessidades dos clientes e características da qualidade do serviço, o que restringe sua aplicação. Além disso, constata-se que o método é geralmente aplicado em conjunto com outras ferramentas, de modo a complementar algumas de suas limitações. Finalmente, verifica-se que o QFD quando aplicado ao setor de serviços objetiva principalmente aprimorar serviços já ofertados, sendo relativamente pouco aplicado para o desenvolvimento de novos serviços.

Palavras-chave: QFD. Desdobramento da Função Qualidade. Aplicação. Serviços. Análise teóricoconceitual.

Abstract: The growing competition has forced companies to provide innovative services to exceed customer expectations by ensuring their competitiveness in the market. Understand what the customer needs are and how to meet them it is an imperative for organizations. The quality function deployment (QFD) is a method that seeks to achieve this purpose. In this context, this paper aims to demonstrate QFD applied to the service context through a literature review. To meet these objectives, a structured process of bibliographic search and organization was applied to select and analyze a portfolio of 25 articles strictly linked to the central subject of QFD applied to services. The results show that the use of QFD is frequently restricted to the first matrix and to the survey of customer needs and characteristics of service quality, which limits its application. Moreover, some important findings is that the method is usually applied with other tools in order to fill some of QFD limitations and, when applied to services context, the method is mainly applied in order to improve services that are already offered, not being largely applied on new services development.

Keywords: QFD. Quality Function Deployment. Application. Services. Theoretical analysis. 


\section{INTRODUÇÃO}

O conceito de serviço passa por uma mudança de paradigma, deixa de ser definido apenas como uma categoria de oferta de mercado e passa a representar uma perspectiva de criação de valor; enfatizando as experiências dos clientes (EDVARDSSON, et al., 2012). Sob esta nova perspectiva, alguns dos desafios enfrentados por empresas que prestam serviços estão relacionados à crescente concorrência e ao aumento contínuo das expectativas dos clientes (KANDAMPULLY; BUTLER, 2001), os quais podem ser enfrentados com base no entendimento de quais são essas expectativas (PARASURAMAN, 1998) e como podem ser traduzidas e avaliadas em características de qualidade de serviços. Além disso, os serviços são intangíveis e não podem ser reprocessados ou devolvidos. Mais importante ainda é o fato de que os clientes os contratam baseados na confiança e na expectativa de receber um serviço de excelente qualidade (KANDAMPULLY; BUTLER, 2001). Com isso, percebe-se também que o desenvolvimento de serviços é diferente do desenvolvimento de produtos tangíveis, como aqueles manufaturados por uma indústria (LEE; CHEN, 2009), sendo que um método bastante difundido e relativamente bem sucedido no desenho de serviços (MAZUR, 1997) é o desdobramento da função qualidade (QFD - Quality Fuction Deployment).

O QFD é um método de suporte ao planejamento e desenvolvimento de serviços que fornece às empresas uma maneira estruturada de assegurar a qualidade e satisfazer seus clientes, mantendo assim uma vantagem competitiva sustentável (AKAO, 2004). Esse método é aplicado com diferentes propósitos, tais como a busca pela melhoria de serviços prestados (HSU, 2013; WU; LIN, 2012), desenho de novos serviços (CHEN, et al., 2014; KIM; YOON, 2012) e o planejamento de serviços e suas integrações (LEE; PHAAL; LEE, 2013; GENG, et al., 2011).

Diante desse cenário, este estudo visa demonstrar aplicações do QFD no contexto de serviços por meio de uma revisão de publicações sobre o tema. Especificamente tem-se os seguintes objetivos: (i) identificar os procedimentos disseminados pelo método QFD aplicados nos trabalhos e propósitos buscados pelos autores que os levaram a aplicar o QFD em suas propostas e (ii) evidenciar 
quais são os métodos e ferramentas aplicados simultaneamente ao QFD nas propostas elaboradas pelos autores e quais são setores da economia que têm aplicado o QFD na elaboração de soluções orientadas a serviços. A partir do cumprimento desses objetivos, espera-se contribuir para 0 aumento do conhecimento acerca do QFD aplicado ao setor de serviços sob a perspectiva da literatura.

\section{A LITERATURA SOBRE QFD NO SETOR DE SERVIÇOS}

Sob uma perspectiva inicial da aplicação do QFD orientada ao desenvolvimento de produtos, o QFD trata-se de um método sistemático que propunha que as empresas desenvolvessem seus produtos a partir dos requisitos dos clientes (HSU, 2013). Sob uma perspectiva mais atual, o QFD é considerado como um método orientado ao cliente que transforma as necessidades desses em requisitos técnicos não somente de produtos, mas também de serviços (CHEN, et al., 2014; BÜYÜKÖZKAN; ÇIFÇI, 2012). De qualquer forma, independentemente do conceito apresentado pelos autores, pode-se afirmar que o QFD tem como finalidade buscar a maior satisfação dos clientes e a integração organizacional alinhada aos desejos dos clientes resultando no aumento da rentabilidade das empresas (ZARE MEHRJERDI, 2011; MOTWANI, et al., 2006).

O QFD é desenvolvido com base na "voz do cliente", a qual fornece suporte aos provedores de serviço a endereçar as lacunas encontradas entre as expectativas dos clientes e suas experiências reais, de modo a priorizar oportunidades de melhorias para desenvolver estratégias empresariais adequadas e assim maximizar o uso de recursos das organizações (HSU, 2013). O método tem sido amplamente utilizado como um meio de comunicação para equipes multifuncionais a fim de estabelecer relações e trade-offs de forma quantitativa e simplificada (LEE; PHAAL; LEE, 2013), o que cria um foco comum de qualidade que é compartilhado por toda a organização (STUART; TAX, 1996). Esse fato leva a uma coesão que é fundamental no desenvolvimento de serviços de qualidade (ANDRONIKIDIS, et al., 2009). Assim, o QFD não é apenas uma ferramenta metodológica, mas apresenta-se como uma possibilidade que fornece meios de traduzir as necessidades dos clientes em cada estágio de desenvolvimento dos 
serviços (CHAN; WU, 2002). Sua aplicação bem sucedida pode resultar num melhor foco no cliente, lead time mais enxuto e retenção do conhecimento (LIU, 2009).

Um processo de QFD bem estabelecido é capaz de demonstrar os requisitos dos clientes, especificações de serviços, metas e desempenho esperado por meio de uma matriz de planejamento. Além disso, a aplicação do QFD no setor de serviços tem apresentado exemplos relevantes nos últimos anos em diversos setores, tais como: educação (WU; LIN, 2012; CHEN; CHOU, 2011), saúde (KUO, et al., 2011; YEH, 2010), manufatura (LI, et al., 2012; GENG, et al., 2011), e turismo (LIN; HUANG; YEH, 2012).

O amplo emprego do QFD é explicado pelos vários benefícios gerados e, essencialmente, por não haver um limite definido para seu potencial de aplicação (CHAN e WU, (2002). Para o setor de serviços, os seguintes benefícios podem ser exemplificados: tradução de requisitos de pacientes em técnicas hospitalares (BOSSERT, 1990); suporte a definição de plano de integração produto-serviço a partir da análise de prioridades (LEE; PHAAL; LEE, 2013) e auxílio no desenvolvimento e priorização de planos viáveis que buscam a melhoria de serviços prestados.

Porém, o QFD também apresenta algumas lacunas em determinadas etapas de seu processo de aplicação. Algumas dificuldades levantadas na literatura são: tradução de demandas dos clientes em características mensuráveis de serviço (CHEN; CHEN; LIN, 2004); má definição do nível de relacionamento entre as necessidades do cliente e as características dos serviços e produtos (BOUCHEREAU; ROWLANDS, 2000); dificuldade e complexidade em avaliar a relação existente entre os requisitos dos clientes e as características dos serviços (GARIBAY; GUTIÉRREZ; FIGUEROA, 2010; YEH, 2010); e consideração de linearidade no relacionamento entre requisitos dos clientes e atributos do serviço (KARSAK; SOZER; ALPTEKIN, 2003).

Por fim, percebe-se que o QFD tem sido um importante método aplicado ao desenvolvimento ou melhoria de serviços, não se restringindo apenas à concepção de produtos para o qual foi inicialmente elaborado. 


\section{MÉTODOS ADOTADOS}

Segundo Torraco (2005), artigos orientados a revisões da literatura requerem dos autores uma análise que se baseie em linhas teóricas de destaque e em modelos reconhecidos cientificamente ou em visões de mundo acerca do tema. Sendo assim, essa perspectiva foi utilizada como base para o presente estudo.

O objetivo geral e os objetivos específicos do presente trabalho são mostrados na Erro! Fonte de referência não encontrada.. Os objetivos e delimitações foram adotados de acordo com o entendimento dos autores, sendo que apenas o objetivo geral foi definido anteriormente à seleção e leitura dos artigos selecionados. Os objetivos específicos foram definidos de maneira iterativa a partir da realização das atividades de seleção e análise de conteúdo do portfólio bibliográfico. Essas atividades também são ilustradas na Figura 1.

Figura 1 - Propósitos do presente estudo

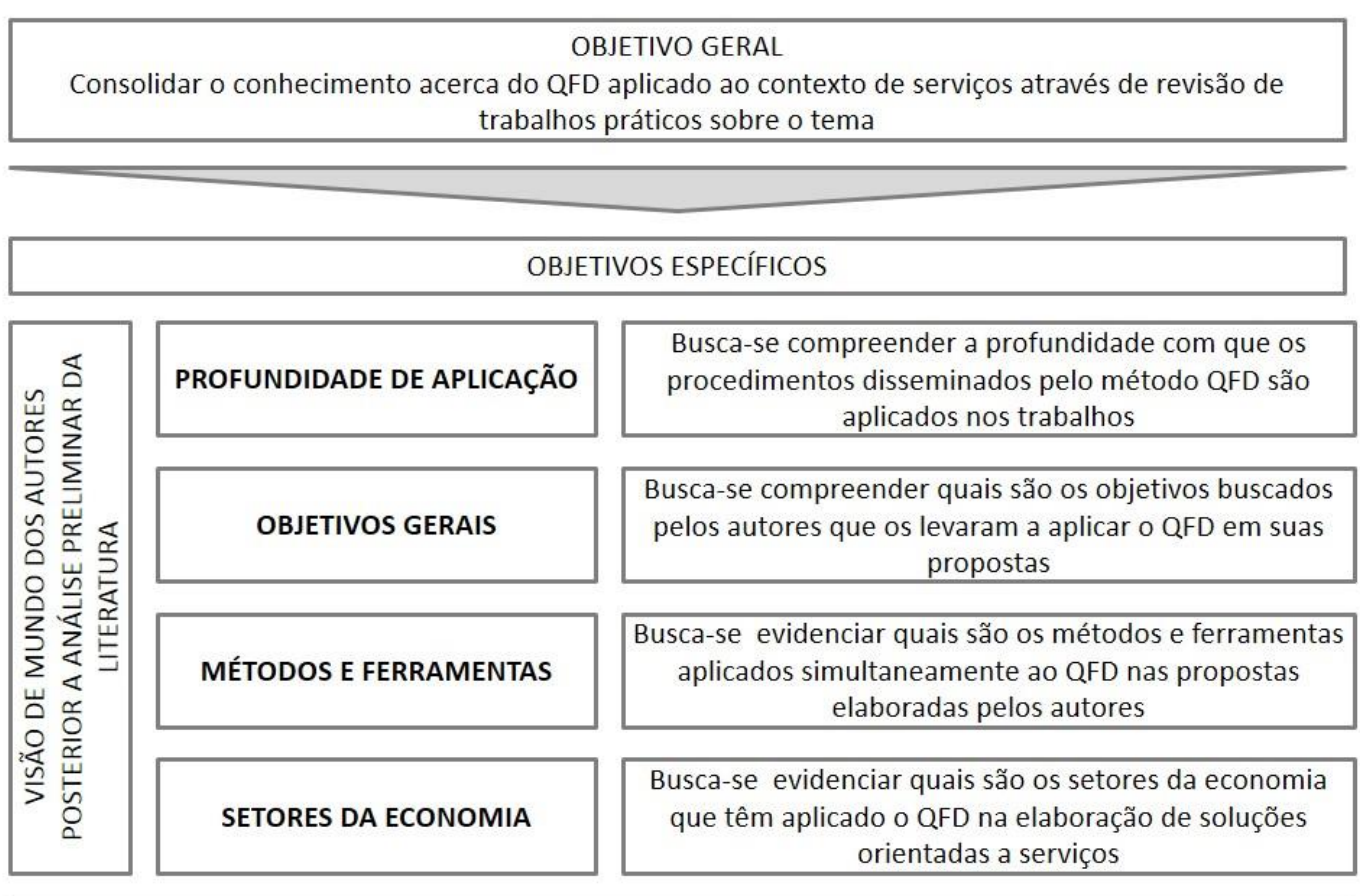

CONTRIBUIÇÃO GERADA

Aumento do conhecimento acerca do QFD aplicado ao setor de serviços sob as perspectivas práticas e teóricas

Fonte: elaborado pelos autores com base na estruturação metodológica da pesquisa 
O presente trabalho foi desenvolvido com base nas seguintes questões de pesquisa: (i) Quais são os autores e artigos atuais e relevantes na literatura científica que aplicam o QFD em serviços? (ii) Como esses autores desenvolvem suas propostas?

Para isso, cinco etapas foram realizadas para a seleção do conjunto bibliográfico e da análise de conteúdo. Primeiramente, definiu-se o objetivo geral e a contribuição que se buscava com o estudo, sem ainda ter claro quais seriam os objetivos específicos. Posteriormente, foi realizada a seleção do conjunto bibliográfico com artigos proeminentes sobre o tema, cujo processo está descrito mais a frente. Em seguida, foram definidos os objetivos específicos com base no entendimento do tema provido pelas etapas anteriores. Em quarto lugar realizou-se a análise do conjunto bibliográfico para cumprir os objetivos definidos. Por último, realizou-se a síntese do conhecimento que emergiu a partir da revisão da literatura de modo a atender a proposta do estudo. A seguir, apresenta-se o processo que norteou a seleção do conjunto bibliográfico.

\subsection{Seleção do Portfólio Bibliográfico}

Uma vez que o tema de pesquisa foi definido pelos pesquisadores, partiu-se então para a execução do processo de seleção e análise de um portfólio bibliográfico. Este portfólio corresponde a um conjunto delimitado de artigos com reconhecimento científico, bem como título, resumo e conteúdo completo, alinhados com o tema de pesquisa determinado pelo pesquisador, segundo suas restrições (LACERDA; ENSSLIN; ENSSLIN, 2014).

A Erro! Fonte de referência não encontrada. ilustra um fluxograma do processo empregado na seleção do portfólio bibliográfico, baseado em procedimentos mais simplificados de Dutra et al. (2015), Ensslin et al. (2014) e Valmorbida et al. (2014). As delimitações desse portfólio são as seguintes:

- Base de dados: ISI Web of Knowledge, uma vez que esta base pode ser considerada referência no meio científico, sendo que retornou um número representativo de publicações aderentes ao tema.

- Palavras-chave: simples e combinadas para a busca na base de dados, a saber: foram "QFD", "quality function deployment", e "service". 
- Período de publicação: entre 2008 e 2015, já que se almejava explorar apenas a literatura mais recente.

- Natureza das publicações: artigos com teor prático que aplicam o QFD em serviços.

- Demais delimitações: apenas publicações em inglês e em periódicos (livros, editoriais, trabalhos em eventos, etc., não foram considerados).

Como resultado, obteve-se um portfólio de 25 publicações alinhadas ao tema de pesquisa, em relação ao título, resumo e conteúdo.

Figura 2 - Fluxograma do processo para seleção do portfólio bibliográfico

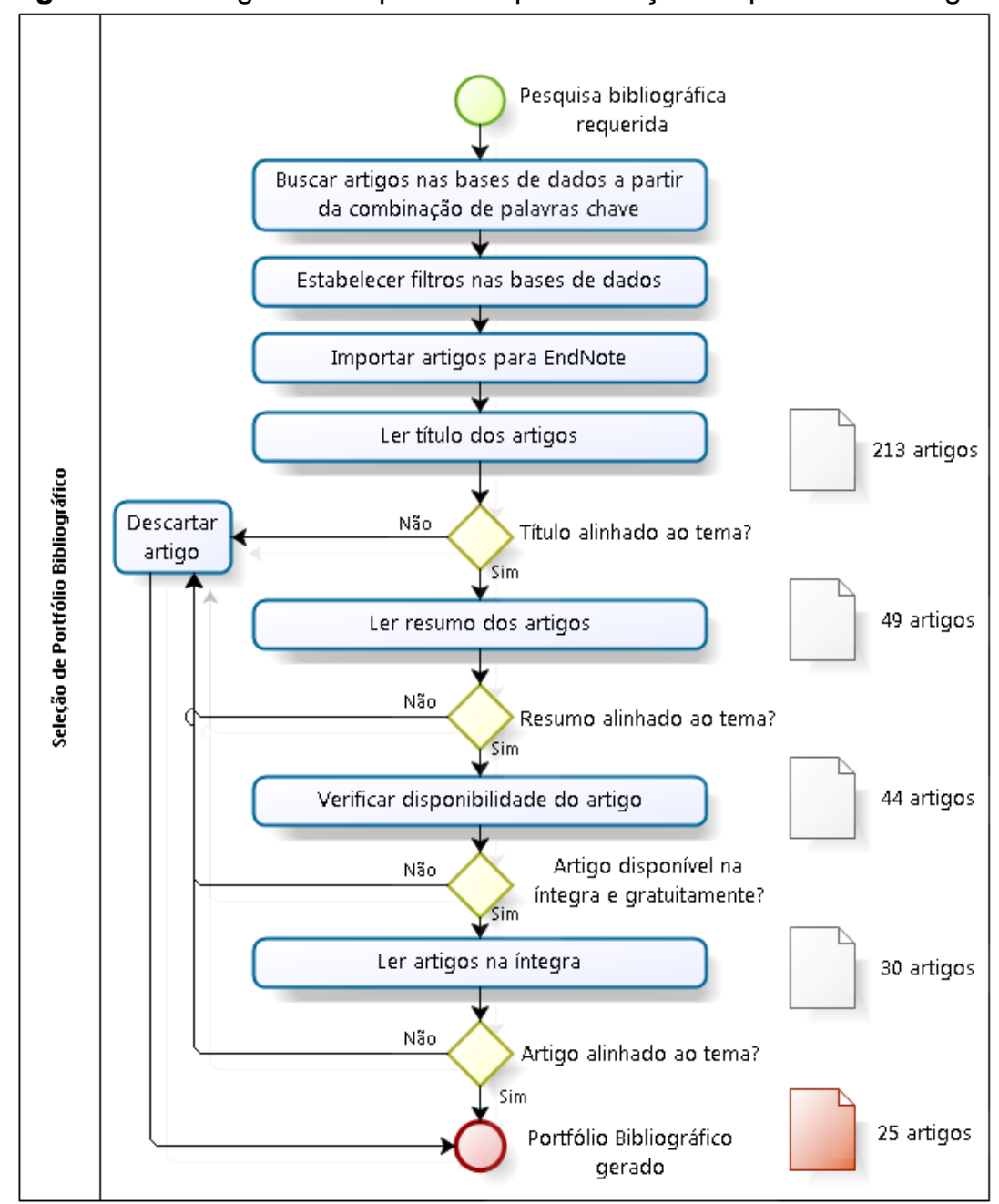

Fonte: elaborado pelos autores com base no processo metodológica da pesquisa 


\section{PRINCIPAIS RESULTADOS E DISCUSSÕES}

Este tópico tem como objetivo apresentar os dados demográficos, síntese e análise das publicações constantes no portfólio bibliográfico.

\subsection{Dados demográficos do estudo}

Com o objetivo de aumentar o conhecimento acerca do tema estudado e suportar o desenvolvimento das próximas etapas, realizou-se inicialmente uma análise demográfica das publicações que compõem o portfólio bibliográfico quanto à identificação de palavras-chave, ferramentas e técnicas empregadas como suporte a aplicação do QFD, metodologias empregadas concomitantes ao QFD, áreas de aplicações em serviços e periódicos em que os artigos foram publicados. Salienta-se que as palavras-chave foram buscadas no título, no abstract e nas palavras-chave das publicações.

Sendo assim, evidencia-se uma grande diversidade de palavras-chave encontradas (em um total de 60), com destaque para "quality fuction deployment" e "QFD", o que era previsível dado o tema de estudo. Além deste termo, outras palavras-chave correlatas, e que abordam o emprego do QFD de maneira simplificada, também apareceram com alguma importância, tais como: "HoQ" (menção ao termo house of quality ou "casa da qualidade"), "customer requirement" e "engineering characteristics". As demais palavras-chave em geral especificam o estudo, tais como áreas de aplicação ("freight containers", "port logistics centre", "port of kaohsiung"), outras metodologias e ferramentas aplicadas no estudo ("Kano model", "fuzzy integral"), etc.

Com relação às ferramentas e técnicas que são aplicadas concomitantemente ao QFD, com base na freqüência de palavras-chave foi possível aferir a importância da "lógica fuzzy" (termo presente com frequência de 7 vezes), "modularidade" (frequência de 5 vezes) e "modelo Kano" (frequência de 3 vezes). Já em relação à finalidade do desenvolvimento do estudo, verifica-se com destaque as palavras "service/product-service planning/design/roadmap", 10 vezes, e "service quality" e suas variáveis, com freqüência de 6 . Essas últimas reforçam a tendência para um 
conceito emergente, sistemas produto-serviço (PSS - Product Service System), e para a crescente preocupação com a qualidade dos serviços prestados, assim como o emprego do QFD em soluções para desenho, planejamento e plano de implantação de novos serviços, enquadramento empregado na análise da literatura posterior. Por fim, percebe-se que a área logística é proeminente entre os objetos de estudo, uma vez que o termo "logistic" e suas variáveis e termos afins (por exemplo: "port", "container") surgem 8 vezes entre as palavras-chave do portfólio bibliográfico, enquanto termos relacionados a qualidade aparecem 2 vezes ("quality management" e outros termos mais específicos, como "Mobile communication systems", "electronic commerce service", "HR strategy", "smart city planning and development", e "distance education and telelearning").

Outra verificação destaca quais são os periódicos presentes no portfólio bibliográfico, assim como a determinação da relevância considerando o fator de impacto SJR (Scientific Journal Ranking). Nessa análise percebe-se uma dispersão das publicações (22 periódicos para 25 artigos). Entre os 22 periódicos, aquele com maior destaque foi o Computers \& Education, com SJR de 2,608. A lista completa de periódicos pode ser vista no Apêndice 1.

Além disso, também é possível verificar a presença de três periódicos que estão dissociados das áreas de engenharia e administração, tais como American Journal of Community Psychology, Journal of Academic Librarianship e o periódico Archives of Gerontology and Geriatrics, fato este que evidencia o emprego do QFD a serviços de natureza diversa.

\subsection{Síntese e análise das publicações}

Em seguida, as publicações do portfólio bibliográfico são analisadas com base nos objetivos do trabalho. Uma síntese das publicações é mostrada no Quadro 1.

\subsubsection{Análise sobre a aplicação do QFD nos artigos}

O QFD é um método introduzido com relativo sucesso no setor de serviços já que oferece um guia estruturado para converter as exigências dos clientes em 
características de novos serviços (ANDRONIKIDIS, et al., 2009). Além disso, envolve a construção de uma ou mais matrizes que orientam as decisões detalhadas que devem ser feitas durante todo o processo de desenvolvimento de serviços (COHEN, 1995). É dentro desse contexto que se procura compreender de que forma e com qual profundidade o QFD vem sendo aplicado nesse setor.

Não somente a conceituação do que vem a ser QFD, como suas aplicações, muitas vezes ficam restritas à primeira matriz, sendo que expressiva parcela (cerca de três quartos dos estudos analisados) aplica essa matriz para levantar os requisitos dos clientes e as características dos serviços (LAM; DAI, 2015; CHEN, et al., 2014; LIAO; KAO, 2014; HSU, 2013; ZUO, et al., 2013; LI, et al., 2012; LIANG; DING; PAN, 2012; LIN; HUANG; YEH, 2012; CHEN; CHOU, 2011; DROR; SUKENIK, 2011; GENG, et al., 2011; LIN; PEKKARINEN, 2011; GARIBAY; GUTIÉRREZ; FIGUEROA, 2010; JANDAGHI; AMIRI; MOLLAEE, 2010; YEH, 2010; DING, 2009; LEE; CHEN, 2009; DANIELS; SANDLER, 2008). Por outro lado, são poucos os artigos que empregam o QFD em maior profundidade, sendo destaque os estudos de An et al. (2008) e de Lin and Pekkarinen (2011).

An et al. (2008) apresentam uma proposta de processo de roadmapping para desenvolvimento de sistemas produto-serviço no setor de telecomunicações, em que o QFD é utilizado ao se desdobrar o planejamento do produto-serviço até o planejamento de controle do processo. Lin e Pekkarinen (2011) apresentam uma proposta de framework para o desenho de serviços logísticos, desde a identificação das necessidades dos clientes até os desdobramentos operacionais destes serviços.

Por fim, é perceptível a utilização das etapas inicias do QFD em detrimento de suas etapas seguintes, tais como os desdobramentos operacionais, seja isso em função do escopo restrito das propostas dos artigos, seja pela utilização de outras ferramentas e métodos ao invés do QFD. 
Quadro 1 - Síntese das publicações construída com base na revisão da literatura

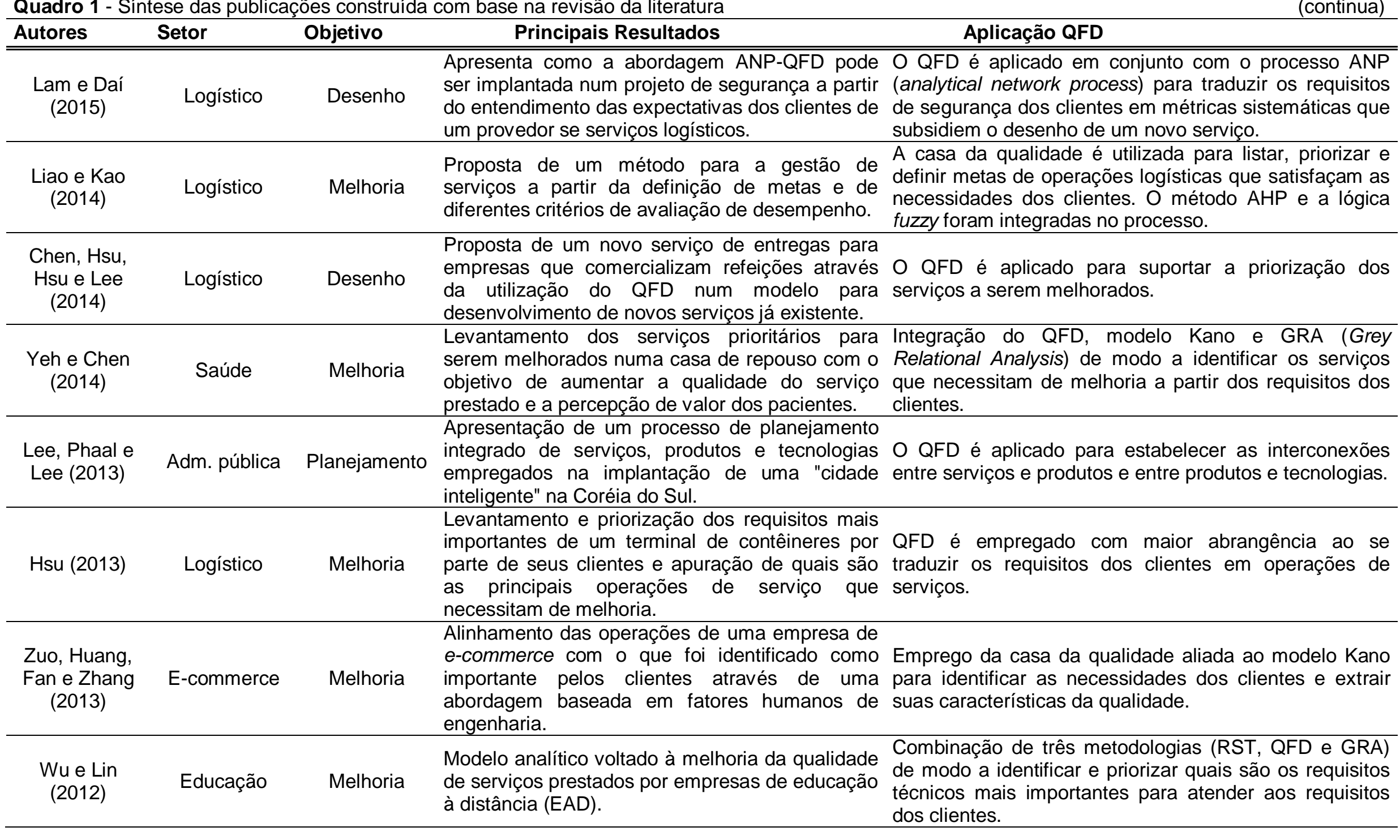


Quadro 2 - Síntese das publicações construída com base na revisão da literatura

\begin{tabular}{|c|c|c|c|c|}
\hline Autores & Setor & Objetivo & Principais Resultados & Aplicação QFD \\
\hline $\begin{array}{l}\text { Liang, Ding } \\
\text { e Pan } \\
\text { (2012) }\end{array}$ & Logístico & Melhoria & $\begin{array}{l}\text { Proposta para se avaliar o impacto de soluções } \\
\text { que visam aumentar a qualidade dos serviços de } \\
\text { centros logísticos de Taiwan. }\end{array}$ & $\begin{array}{l}\text { A lógica fuzzy é aderida ao QFD para se levantar os } \\
\text { requisitos de qualidade de serviços e as soluções } \\
\text { encontradas para cada um deles. }\end{array}$ \\
\hline $\begin{array}{l}\text { Kim e Yoon } \\
\text { (2012) }\end{array}$ & Car sharing & Desenho & $\begin{array}{l}\text { Apresentação de uma abordagem para a criação } \\
\text { de novos conceitos de sistemas produto-serviço } \\
\text { (PSS) através da resolução de contradições } \\
\text { entre componentes de serviço e produto. }\end{array}$ & $\begin{array}{l}\text { O QFD é empregado para se levantar as } \\
\text { características críticas de produtos e serviços. Além } \\
\text { disto, a partir do estudo de caso, conclui-se que a } \\
\text { integração entre o método TRIZ e o QFD pode } \\
\text { prevenir inconsistências que ocorrem no desenho de } \\
\text { soluções produto-serviço. }\end{array}$ \\
\hline $\begin{array}{l}\text { Lin, Huang } \\
\text { e Yeh } \\
(2012)\end{array}$ & Turismo & Melhoria & $\begin{array}{l}\text { Análise de critérios para avaliação de } \\
\text { desempenho de serviços, o que permite } \\
\text { identificar lacunas entre o que é esperado pelo } \\
\text { cliente e o que a organização acredita entregar, } \\
\text { suportando, assim, a tomada de decisão visando } \\
\text { a melhoria do sistema. }\end{array}$ & $\begin{array}{l}\text { A casa da qualidade é aplicada sob a lógica fuzzy } \\
\text { para levantar os requisitos dos clientes e propor e } \\
\text { priorizar serviços que atendam aos mesmos. }\end{array}$ \\
\hline $\begin{array}{c}\text { Geum, } \\
\text { Kwak e } \\
\text { Park (2012) }\end{array}$ & Restaurante & Desenho & $\begin{array}{l}\text { Proposta de um framework para a modularização } \\
\text { de serviços, algo pouco visto na literatura sob o } \\
\text { viés prático, segundo os autores. }\end{array}$ & $\begin{array}{l}\text { A estrutura da Casa da Qualidade é modificada para } \\
\text { se apurar s componentes de serviços modularizáveis } \\
\text { com os módulos de serviços propostos. }\end{array}$ \\
\hline $\begin{array}{l}\mathrm{Li}, \mathrm{Ji}, \mathrm{Cu} \\
\text { Qi e Tang } \\
(2012)\end{array}$ & Manufatura & Desenho & $\begin{array}{l}\text { Sugestão de um processo de desenho modular } \\
\text { de produtos/serviços cujo objetivo é a redução do } \\
\text { número de serviços/produtos durante o processo } \\
\text { fabril de uma indústria. }\end{array}$ & $\begin{array}{l}\text { A Casa da Qualidade é utilizada para apurar quais } \\
\text { são os serviços vinculados às requisições dos cliente } \\
\text { de maneira concomitante ao método de partição e } \\
\text { integração modular. }\end{array}$ \\
\hline $\begin{array}{l}\text { Dror e } \\
\text { Sukenik } \\
(2011)\end{array}$ & Banco & Melhoria & $\begin{array}{l}\text { Proposta de framework que explicita quais são } \\
\text { as características dos serviços prestados por um } \\
\text { call-center que necessitam de melhoria. }\end{array}$ & $\begin{array}{l}\text { O QFD é aplicado para traduzir quais são } \\
\text { necessidades internas de melhoria a partir das } \\
\text { deficiências levantadas previamente. }\end{array}$ \\
\hline $\begin{array}{l}\text { Geng, Chu, } \\
\text { Xue e } \\
\text { Zhang } \\
\text { (2011) }\end{array}$ & Manufatura & Planejamento & $\begin{array}{l}\text { Apresentação de uma abordagem para a tomada } \\
\text { de decisão orientada ao planejamento de } \\
\text { sistemas produto-serviços (PSS). }\end{array}$ & $\begin{array}{l}\text { O QFD é empregado para traduzir os requisitos do } \\
\text { cliente em características de engenharia e serviços. O } \\
\text { modelo Kano, a lógica fuzzy e a DEA também são } \\
\text { empregados. }\end{array}$ \\
\hline $\begin{array}{l}\text { Chen e } \\
\text { Chou } \\
(2011)\end{array}$ & Educação & Melhoria & $\begin{array}{l}\text { Identificação das ações chave para } \\
\text { aperfeiçamento dos serviços prestados por uma } \\
\text { biblioteca. }\end{array}$ & $\begin{array}{l}\text { A matriz da casa da qualidade é aplicada para } \\
\text { levantar e priorizar as necessidades dos usuários. Já } \\
\text { o método GRA afere a relação entre as necessidades } \\
\text { levantadas e as soluções propostas. }\end{array}$ \\
\hline
\end{tabular}


Quadro 3 - Síntese das publicações construída com base na revisão da literatura

\begin{tabular}{|c|c|c|c|}
\hline Autores & Setor & Objetivo & Principais Resultados \\
\hline $\begin{array}{l}\text { Kuo, Wu, } \\
\text { Hsu e Chen } \\
\quad(2011)\end{array}$ & Saúde & Melhoria & 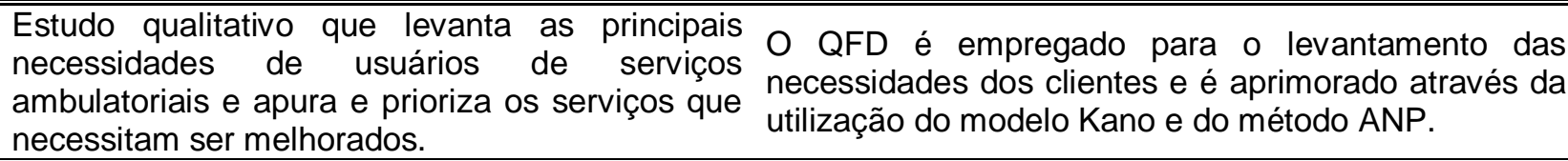 \\
\hline $\begin{array}{l}\text { Lin e } \\
\text { Pekkarinen } \\
(2011)\end{array}$ & $\begin{array}{l}\text { Logí } \\
\text { stico }\end{array}$ & Desenho & $\begin{array}{l}\text { Proposta de um framework para o desenho de A casa da qualidade e a lógica de módulos são } \\
\text { serviços logísticos, desde a identificação das integradas para desenvolver a proposta. Destaca-se o } \\
\text { necessidades dos clientes aos desdobramentos desdobramento da função qualidade até o nível } \\
\text { operacionais do serviço. } \\
\text { operacional. }\end{array}$ \\
\hline $\begin{array}{l}\text { Jeaghi, } \\
\text { Amiri e } \\
\text { Mollaee } \\
(2010)\end{array}$ & $\mathrm{RH}$ & Melhoria & $\begin{array}{ll}\text { Opresentação de uma ferramenta para aumentar } & \text { Qstratégias de RH adotadas por uma organização, } \\
\text { a satisfação dos clientes de entidades públicas. } & \begin{array}{l}\text { assim como para aferir a correlação entre essas e as } \\
\text { necessidades dos clientes. }\end{array}\end{array}$ \\
\hline Yeh (2010) & Saúde & Melhoria & 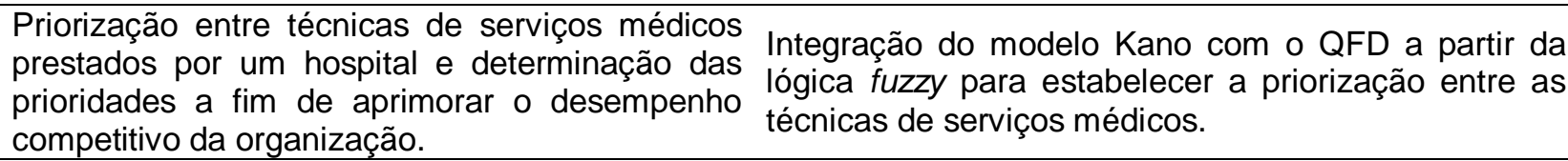 \\
\hline $\begin{array}{l}\text { Garibay, } \\
\text { Gutierrez e } \\
\text { Figueroa } \\
(2010)\end{array}$ & Educação & Melhoria & 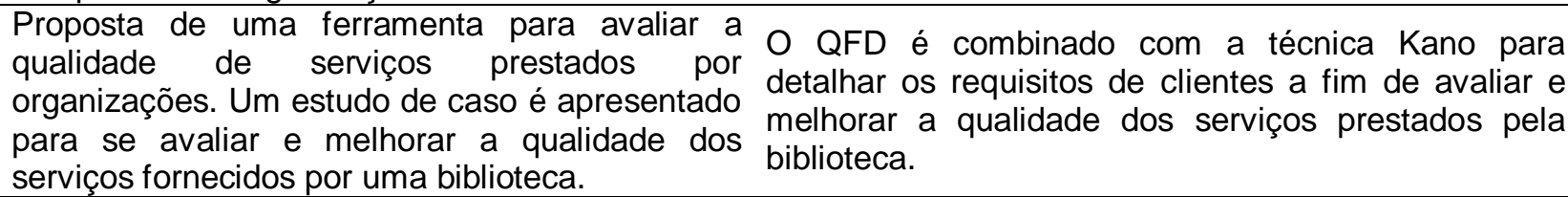 \\
\hline $\begin{array}{l}\text { Lee e Chen } \\
\qquad(2009)\end{array}$ & $\begin{array}{l}\text { Educação e } \\
\text { restaurante }\end{array}$ & Desenho & 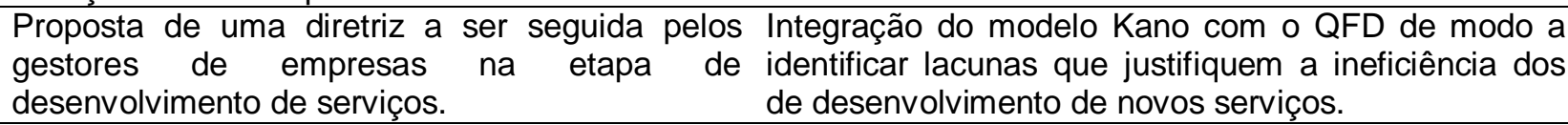 \\
\hline Ding (2009) & Logístico & Melhoria & $\begin{array}{l}\text { Identificação de potenciais soluções para o Através da matriz da casa da qualidade - e } \\
\text { sistema de serviço de entregas de um porto, suportadas pela lógica fuzzy - são levantadas as } \\
\text { onde são levantados os itens mais importantes e necessidades dos clientes, assim como alternativas } \\
\text { soluções prioritárias na melhoria dos serviços. }\end{array}$ \\
\hline $\begin{array}{c}\text { An, Lee e } \\
\text { Park (2008) }\end{array}$ & $\begin{array}{l}\text { Telecomunic } \\
\text { ações }\end{array}$ & Planejamento & $\begin{array}{l}\text { Proposta de uma estrutura e processo de } \begin{array}{l}\text { O QFD é utilizado ao se desdobrar o planejamento do } \\
\text { roadmapping para desenvolvimento de sistemas } \\
\text { produto-serviço }\end{array} \\
\text { produto até o planejamento de controle do processo. }\end{array}$ \\
\hline $\begin{array}{l}\text { Daniels e } \\
\text { Seler } \\
(2008)\end{array}$ & $\begin{array}{l}\text { Adm. } \\
\text { pública }\end{array}$ & Desenho & $\begin{array}{l}\text { Proposta de um conjunto padrão de serviços que } \text { O QFD é aplicado com abrangência, partindo desde o } \\
\text { poderia ser implantado em diferentes instituições levantamento das necessidades dos clientes à análise } \\
\text { que prestem suporte à prevenção da saúde dos benefícios gerados ao se implantar determinadas } \\
\text { mental. }\end{array}$ \\
\hline
\end{tabular}

Revista Produção Online, Florianópolis, SC, v. 17, n. 1, p. 268-294, jan./mar. 2017 


\subsubsection{Análise sobre os objetivos gerais dos artigos}

Quanto aos objetivos gerais das publicações, esses foram agrupados em três diferentes finalidades: a) Melhorar os serviços já prestados; b) Desenhar novos serviços; c) Planejar serviços e suas integrações. Essa segmentação foi definida posteriormente à análise dos dados demográficos dos artigos selecionados.

Dentre esses grupos, destaca-se o objetivo de "melhorar os serviços já prestados" entre os estudos analisados, presente em mais da metade (56\%) das publicações (LIAO; KAO, 2014; YEH; CHEN, 2014; HSU, 2013; ZUO, et al., 2013; LIANG; DING; PAN, 2012; LIN; HUANG; YEH, 2012; WU; LIN, 2012; CHEN; CHOU, 2011; DROR; SUKENIK, 2011; KUO, et al., 2011; GARIBAY; GUTIÉRREZ; FIGUEROA, 2010; JANDAGHI; AMIRI; MOLLAEE, 2010; YEH, 2010; DING, 2009).

A relevância do objetivo em melhorar serviços já prestados explicita a importância do QFD no que tange a identificação dos requisitos dos clientes, levantamento dos serviços para atender a esses requisitos e, por fim, a priorização dos serviços a serem aprimorados. A priorização desses serviços, no entanto, muitas vezes não é realizada a partir do levantamento entre o desempenho esperado de determinado serviço e/ou requisito e o que é atualmente entregue, mas apenas baseado na importância de cada serviço frente aos requisitos dos clientes. A implicação disso seria a priorização de serviços que, mesmo importantes segundo os clientes, já apresentam níveis de desempenho excelente, enquanto serviços não priorizados podem apresentar desempenho comprometedor e não ser atacados.

Ao longo dos anos, diversos autores - Ding (2009), Garibay et al. (2010), Yeh (2010), Dror e Sukenik (2011), Lin e Pekkarinen (2011), Chen e Chou (2011), Lin et al. (2012), Zuo et al. (2013), Liao e Kao (2014), e Yeh e Chen (2014) vem embasando suas sugestões de melhorias a partir da identificação da lacuna entre o desempenho esperado de determinados serviços e/ou requisitos dos clientes frente ao desempenho atual. Por outro lado, outros autores (e.g. JANDAGHI et al., 2010; KUO, et al., 2011; LIANG; DING; PAN, 2012; e WU; LIN, 2012) priorizam os serviços a serem melhorados a partir do impacto de determinado serviço na satisfação do cliente sem levar em consideração o nível atual de desempenho desses.

Enquanto isso, o objetivo de "desenhar novos serviços", em praticamente um terço das publicações (DANIELS; SANDLER, 2008; LEE; CHEN, 2009; LIN; PEKKARINEN, 2011; GEUM; KWAK; PARK, 2012; KIM; YOON, 2012; LI, et al., 
2012; CHEN, et al., 2014; LAM; DAI, 2015) e a busca de "planejar serviços e suas integrações" (em 12\% dos total de publicações) (AN et al., 2008; GENG, et al., 2011; LEE et al., 2013) aparecem com maior discrição quando comparado à busca pela melhoria de serviços.

A Figura 3 apresenta a segmentação dos 25 artigos do portfólio bibliográfico por objetivo pretendido pelo estudo ao aplicar O QFD. O objetivo de melhorar serviços surge em mais da metade do total de publicações analisadas, enquanto que de desenhar novos serviços aparece em aproximadamente um terço; o propósito de planejar serviços e integrações aparece em pouco mais de $10 \%$ do total de publicações). Cabe ressaltar que a finalidade aqui não é enfatizar as proporções de trabalhos, uma vez que o portfolio é relativamente pequeno, mas sim ilustrar quais são os elementos mais freqüentes que estão presentes no total de publicações analisado.

Figura 3 - Número de artigos do portfólio bibliográfico por objetivo do estudo

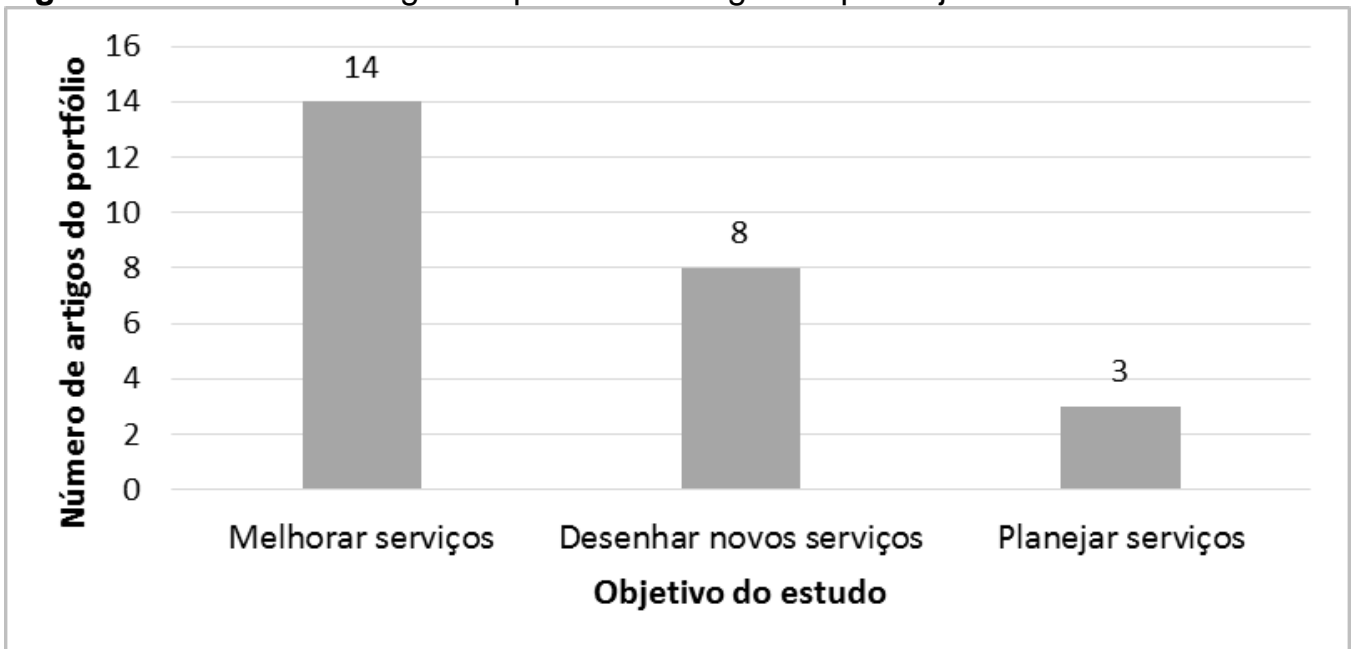

Fonte: elaborado pelos autores com base na busca, organização e análise bibliográfica

\subsubsection{Métodos e ferramentas utilizados concomitantemente ao QFD}

Embora o QFD seja uma reconhecida metodologia para aumentar a satisfação dos clientes com base no entendimento de suas necessidades (CHAN; WU, 2002; BOUCHEREAU; ROWLANDS, 2000) e para aprimorar o desenho de serviços que atendam ou excedam as expectativas dos clientes (ANDRONIKIDIS, et al., 2009), algumas limitações são apresentadas. Dentre as limitações encontradas, pode-se mencionar a necessidade de lidar com grandes quantidades de dados 
coletados de clientes, de concorrentes e de equipes (ANDRONIKIDIS, et al., 2009), a dificuldade e morosidade em avaliar as relações entre cada um dos requisitos do cliente e características do serviço, bem como as correlações entre as diversas características do serviço (BOUCHEREAU; ROWLANDS, 2000) e a voz do cliente conter ambiguidades e significados diferentes devido ao fato de nem todos terem a mesma percepção de uma descrição linguística especial (CHAN; WU, 2005; EROL; FERRELL JR, 2003).

Frente a essas limitações apresentadas pelo QFD é que diversos autores utilizam outras metodologias e ferramentas para preencher essas lacunas, sendo que no portfólio bibliográfico resultante destaca-se a utilização do modelo Kano em cerca de 30\% das publicações (YEH; CHEN, 2014; ZUO, et al., 2013; GENG, et al., 2011; KUO, et al., 2011; GARIBAY; GUTIÉRREZ; FIGUEROA, 2010; YEH, 2010; LEE; CHEN, 2009), o emprego da lógica fuzzy em quase um quarto das publicações (LIAO; KAO, 2014; LIANG; DING; PAN, 2012; LIN; HUANG; YEH, 2012; GARIBAY; GUTIÉRREZ; FIGUEROA, 2010; YEH, 2010; DING, 2009) e a utilização do GRA Grey Relational Analysis em pouco mais de 10\% das publicações (YEH; CHEN, 2014; WU; LIN, 2012; CHEN; CHOU, 2011).

O GRA trata-se de uma teoria que busca examinar fatores que afetam determinado sistema a partir de uma pequena base de dados. Cita-se como exemplo uma validação da relação entre técnicas para melhorar a qualidade de serviços de uma biblioteca e as necessidades dos clientes (CHEN, 2011). O modelo Kano também surge nos trabalhos e é, em regra, empregado com o objetivo de capturar e priorizar a voz do cliente (GARIBAY; GUTIÉRREZ; FIGUEROA, 2010), enquanto a lógica fuzzy é utilizada para transformar informações subjetivas ou imprecisas em quesitos mensuráveis, cujo exemplo é a aferição da relação entre requisitos de clientes e características de serviços do porto de Kaohsiung por meio da avaliação subjetiva de especialistas (DING, 2009).

A Figura 4 apresenta a frequência das principais metodologias e ferramentas empregadas em conjunto com o QFD em relação ao total de artigos do portfólio bibliográfico. Verifica-se que o Modelo Kano é aplicado em quase $30 \%$ do total de publicações, que a Lógica fuzzy é aplicada em quase um quarto, e que o GRA é aplicado em pouco mais de $10 \%$ do total de publicações. As metodologias e ferramentas não apresentadas no gráfico da Figura 4 aparecem de maneira menos representativa no restante das publicações do portfólio bibliográfico. 
Figura 4 - Número de artigos do portfólio bibliográfico de acordo com as principais metodologias e ferramentas empregadas em conjunto com o QFD

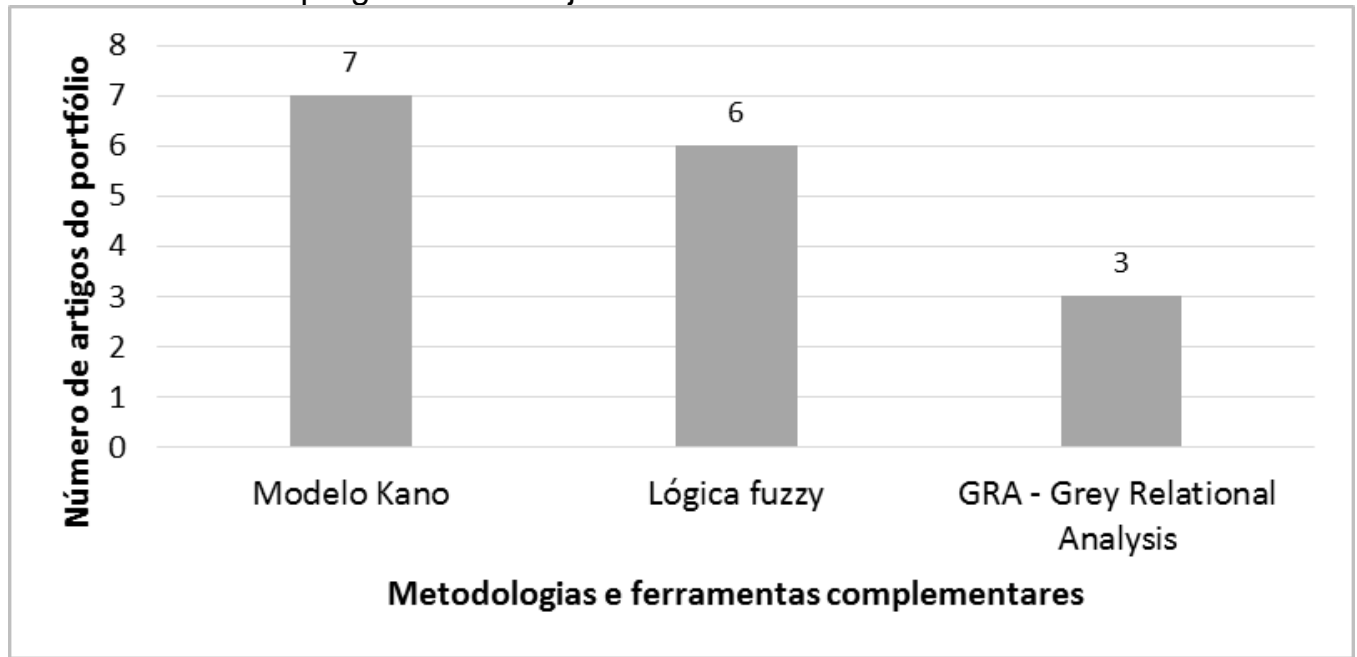

Fonte: elaborado pelos autores com base na busca, organização e análise bibliográfica

Com base nessas constatações, permite-se inferir que os estudos, em geral, não se restringem a uma aplicação exclusiva do QFD, empregando também outras metodologias e ferramentas de maneira complementar.

\subsubsection{Análise sobre as áreas e setores econômicos presente nas publicações}

Outro aspecto importante para ser analisado são os setores em que as soluções propostas pelos artigos têm sido aplicadas, de modo a averiguar se há alguma área de concentração mais proeminente. Nesse caso, percebe-se que embora haja uma maior relevância de artigos no setor logístico, outros setores são abordados nos trabalhos, não havendo uma concentração significativa.

Conforme já citado anteriormente, o setor logístico aparece com mais frequência entre os setores abordados nas publicações; em cerca de uma quarto do total de artigos (CHEN, et al., 2014; LIAO; KAO, 2014; HSU, 2013; LIANG; DING; PAN, 2012; LIN; PEKKARINEN, 2011; DING, 2009). Algo que se destaca é a presença de autores de Taiwan, sendo que a única publicação que foge a esse contexto foi desenvolvida por autores do Reino Unido e Finlândia (LIN; PEKKARINEN, 2011). Além disso, verifica-se também uma concentração de estudos logísticos voltados a portos e a terminais de contêineres (HSU, 2013; LIANG; DING; PAN, 2012; DING, 2009). 
É também perceptível uma ampla gama de setores econômicos abordados, tais como: educação (WU; LIN, 2012; CHEN; CHOU, 2011; GARIBAY; GUTIÉRREZ; FIGUEROA, 2010; LEE; CHEN, 2009), saúde (YEH; CHEN, 2014; KUO, et al., 2011; YEH, 2010), administração pública (DANIELS; SANDLER, 2008), telecomunicações (AN; LEE; PARK, 2008), manufatura (LI, et al., 2012; GENG, et al., 2011), e compartilhamento de carros - car sharing (KIM; YOON, 2012). Tal dispersão de setores demonstra a flexibilidade e amplitude de aplicações que o QFD apresenta, podendo ser aplicado desde a busca por melhorias em serviços prestados por um call center de um banco (DROR; SUKENIK, 2011) até o desenho de novos serviços prestados por um restaurante (GEUM; KWAK; PARK, 2012).

\subsection{Discussão dos resultados}

No que se refere à profundidade de aplicação do QFD nas soluções propostas pelos artigos, é evidente a quase exclusividade do emprego da primeira matriz em boa parte das publicações, sendo que muitos autores restringem 0 conceito e aplicação do QFD a essa matriz. Os desdobramentos de matrizes que visam planejar as operações e processos decorrentes das etapas iniciais do QFD (primeira matriz) ainda é algo pouco recorrente e, muitas vezes, sequer citada pelos autores como parte do método.

No que tange aos objetivos finais buscados pelos autores, ressalta-se a busca pela melhoria de serviços já prestados pelas organizações, onde o QFD é utilizado, notadamente, para dar suporte ao levantamento dos requisitos dos clientes e definição das características dos serviços a serem aprimorados a partir dessa apuração inicial. De modo análogo, percebe-se que a concepção e desenho de novos serviços e o planejamento de integrações entre serviços e produtos, por exemplo, também são recorrentes entre as soluções buscadas pelos pesquisadores.

Outro ponto significativo levantado pelo presente trabalho se trata das lacunas apresentadas pelo QFD ao longo de suas etapas de desenvolvimento, sendo essas preenchidas por meio da aplicação concomitante de outras ferramentas e métodos. Dentre essas lacunas, destaca-se a necessidade em tratar grandes quantidades de dados, a dificuldade em avaliar as relações entre requisitos dos clientes e características dos serviços e a dificuldade em traduzir a voz do cliente nessas características, dada à dificuldade de tratar a linguagem falada sem trazer 
distorções de entendimento. São por esses e outros motivos que alternativas como o modelo Kano, a lógica fuzzy, o GRA, entre outros, são utilizados com frequência no desenvolvimento da solução.

Apesar disso, destaca-se a amplitude dos setores abordados pelo QFD. Embora se tenha percebido uma maior concentração da área logística dentre os artigos analisados, as áreas de educação e saúde apareceram com certo destaque, enquanto setores como bancos, restaurantes, car sharing, e administração pública também se fazem presente entre as publicações.

Com tudo isso, afere-se a flexibilidade do método em atender a diferentes situações, não se limitando a um tipo de solução. Essa flexibilidade também é demonstrada por meio da incorporação de outras ferramentas, o que trás a possibilidade de adequar as respostas aos problemas específicos e alinhados com os desejos dos decisores envolvidos.

\section{CONCLUSÕES}

Dada a relevância do desenvolvimento de pesquisa orientado à aplicação do QFD ao setor de serviços, este trabalho teve como objetivo demonstrar aplicações do método no contexto de serviços por meio de uma revisão de publicações sobre o tema. Para a consecução do objetivo, um processo estruturado foi aplicado para a seleção e análise de um portfólio de 25 artigos proeminentes sobre o tema.

Dessa análise, considerando as delimitações empregadas, têm-se os seguintes pontos conclusivos:

- Na maior parte dos estudos, o emprego do QFD se limita a construção da primeira matriz, restringindo o conceito a uma parte do método.

- A busca pela melhoria de serviços já prestados surge com destaque quando comparado a outras aplicações.

- A utilização do QFD apresenta algumas lacunas, sendo essas preenchidas por meio da aplicação de outras metodologias e ferramentas, tais como o modelo Kano e a lógica fuzzy.

- O QFD é aplicado numa gama considerável de segmentos de serviços, mostrando sua flexibilidade de aplicação. Dentre esses segmentos, a área logística apareceu de forma mais incisiva frente as demais. 
A compreensão de como os estudos contemporâneos analisados neste trabalho tem aplicado o QFD no setor de serviços pode ser considerada como uma referência na busca de novas maneiras para se atingir os desafios organizacionais atuais. Este fato é constado, particularmente, nas aplicações no setor de prestação de serviços. Como continuidade do presente trabalho, pretende-se ampliar esta análise de aplicação do QFD em outros setores econômicos.

Finalmente, qualquer trabalho de pesquisa não é isento de limitações. Mesmo baseado em um método de revisão literária sistemática, trabalhos relevantes podem não ter sido considerados. Além disso, ao empregar uma análise qualitativa, realizada com julgamento próprio, as interpretações podem variar de acordo com a compreensão dos autores, as quais podem não refletir com exatidão as aplicações e soluções apresentadas pelas publicações.

\section{AGRADECIMENTOS}

Os autores agradecem aos avaliadores da Produção OnLine pelas sugestões e recomendações que contribuíram para a melhoria do manuscrito.

\section{REFERÊNCIAS}

AKAO, Y. Quality function deployment. Milwalkee: Productivity Press, 2004.

AN, Y.; LEE, S.; PARK, Y. Development of an integrated product-service roadmap with QFD: A case study on mobile communications. International Journal of Service Industry Management, v. 19, n. 5, p. 621-638, 2008. http://dx.doi.org/10.1108/09564230810903497

ANDRONIKIDIS, A.; GEORGIOU, A.C.; GOTZAMANI, K.; KAMVYSI, K. The application of quality function deployment in service quality management. The TQM Journal, v. 21, n. 4, p. 319-333, 2009. http://dx.doi.org/10.1108/17542730910965047

BOSSERT, J.L. QFD, a Practitioner's Approach. Milwaukee: ASQC Quality Press, 1990.

BOUCHEREAU, V.; ROWLANDS, H. Methods and techniques to help quality function deployment (QFD). Benchmarking: An International Journal, v. 7, n. 1, p. 8-20, 2000. http://dx.doi.org/10.1108/14635770010314891

BÜYÜKÖZKAN, G.; CIFC̣I, G. A new incomplete preference relations based approach to quality function deployment. Information Sciences, v. 206, p. 30-41, 2012.

http://dx.doi.org/10.1016/j.ins.2012.04.010

CHAN, L.-K.; WU, M.-L. Quality function deployment: a comprehensive review of its concepts and methods. Quality Engineering, v. 15, n. 1, p. 23-35, 2002. 
CHAN, L.-K.; WU, M.-L. A systematic approach to quality function deployment with a full illustrative example. Omega, v. 33, n. 2, p. 119-139, 2005.

http://dx.doi.org/doi:10.1016/j.omega.2004.03.010

CHEN, C.-Y.; CHEN, L.-C.; LIN, L. Methods for processing and prioritizing customer demands in variant product design. IIE Transactions, v. 36, n. 3, p. 203-219, 2004. http://dx.doi.org/10.1080/07408170490274188

CHEN, M.-C.; HSU, C.-L.; HSU, C.-M.; LEE, Y.-Y. Ensuring the quality of e-shopping specialty foods through efficient logistics service. Trends in Food Science \& Technology, v. 35, n. 1, p. 69-82, 2014. http://dx.doi.org/10.1016/j.tifs.2013.10.011

CHEN, Y.-T.; CHOU, T.-Y. Applying GRA and QFD to improve library service quality. The Journal of Academic Librarianship, v. 37, n. 3, p. 237-245, 2011.

http://dx.doi.org/10.1016/j.acalib.2011.02.016

COHEN, L. Quality function deployment: how to make QFD work for you. New York: Prentice Hall, 1995.

DANIELS, V.-S.; SANDLER, I. Use of quality management methods in the transition from efficacious prevention programs to effective prevention services. American journal of community psychology, v. 41, n. 3-4, p. 250-261, 2008.

http://dx.doi.org/10.1007/s10464-008-9170-3

DING, J.-F. Applying fuzzy quality function deployment (QFD) to identify solutions of service delivery system for port of Kaohsiung. Quality \& Quantity, v. 43, n. 4, p. 553-570, 2009. http://dx.doi.org/10.1007/s11135-007-9138-7

DROR, S.; SUKENIK, Y. A strategic service quality framework using QFD. Total Quality Management \& Business Excellence, v. 22, n. 10, p. 1057-1070, 2011.

http://dx.doi.org/10.1080/14783363.2011.611329

DUTRA, A.; RIPOLL-FELIU, V. M.; FILLOL, A. G.; ENSSLIN, S. R.; ENSSLIN, L. The construction of knowledge from the scientific literature about the theme seaport performance evaluation. International Journal of Productivity and Performance Management, v. 64, n. 2, p. 243-269, 2015. http://dx.doi.org/10.1108/IJPPM-01-2014-0015

EDVARDSSON, B.; KRISTENSSON, P.; MAGNUSSON, P.; SUNDSTRÖM, E. Customer integration within service development - A review of methods and an analysis of of insitu and exsitu contributions. Technovation, v. 32, n. 7, p. 419-429, 2012.

http://dx.doi.org/10.1016/j.technovation.2011.04.006

ENSSLIN, S.R.; ENSSLIN, L.; LACERDA, R.T.O.; DE SOUZA, V. H. A.. Disclosure of the State of the Art of Performance Evaluation Applied to Project Management. American Journal of Industrial and Business Management, v. 4, n. 11, p. 677, 2014. http://dx.doi.org/10.4236/ajibm.2014.411073

EROL, I.; FERRELL JR, W.G. A methodology for selection problems with multiple, conflicting objectives and both qualitative and quantitative criteria. International Journal of

Production Economics, v. 86, n. 3, p. 187-199, 2003.

http://dx.doi.org/10.1016/S0925-5273(03)00049-5 
GARIBAY, C.; GUTIÉRREZ, H.; FIGUEROA, A. Evaluation of a digital library by means of quality function deployment (QFD) and the Kano model. The Journal of Academic Librarianship, v. 36, n. 2, p. 125-132, 2010.http://dx.doi.org/10.1016/j.acalib.2010.01.002

GENG, X.; CHU, X.; XUE, D.; ZHANG, Z. A systematic decision-making approach for the optimal product-service system planning. Expert Systems with Applications, v. 38, n. 9, p. 11849-11858, 2011. http://dx.doi.org/10.1016/j.eswa.2011.03.075

GEUM, Y.; KWAK, R.; PARK, Y. Modularizing services: A modified HoQ approach. Computers \& Industrial Engineering, v. 62, n. 2, p. 579-590, 2012. http://dx.doi.org/10.1016/i.cie.2011.11.006

HSU, W.-K. K. Improving the service operations of container terminals. The International Journal of Logistics Management, v. 24, n. 1, p. 101-116, 2013. http://dx.doi.org/10.1108/IJLM-05-2013-0057

JANDAGHI, G.; AMIRI, A. N.; MOLLAEE, A. A quality function deployment approach to HR strategy formation and prioritization: Meeting client satisfaction in service organizations.

African Journal of Business Management, v. 4, n. 16, p. 3513, 2010.

KANDAMPULLY, J.; BUTLER, L. Service guarantees: A strategic mechanism to minimise customers' perceived risk in service organisations. Managing Service Quality: an International Journal, v. 11, n. 2, p. 112-121, 2001. http://dx.doi.org/10.1108/09604520110387248

KARSAK, E.; SOZER, S.; ALPTEKIN, S. E. Product planning in quality function deployment using a combined analytic network process and goal programming approach. Computers \& industrial engineering, v. 44, n. 1, p. 171-190, 2003.

http://dx.doi.org/10.1016/S0360-8352(02)00191-2

KIM, S.; YOON, B. Developing a process of concept generation for new product-service systems: a QFD and TRIZ-based approach. Service Business, v. 6, n. 3, p. 323-348, 2012. http://dx.doi.org/10.1007/s11628-012-0138-x

KUO, R.-J.; WU, Y.-H.; HSU, T.-S.; CHEN, L.-K. Improving outpatient services for elderly patients in Taiwan: a qualitative study. Archives of gerontology and geriatrics, v. 53, n. 2, p. e209-e217, 2011.http://dx.doi.org/10.1016/i.archger.2010.09.013

LACERDA, R.T.D. O.; ENSSLIN, L.; ENSSLIN, S.R. Research opportunities in strategic management field: a performance measurement approach. International Journal of Business Performance Management, v. 15, n. 2, p. 158-174, 2014. http://dx.doi.org/10.1504/IJBPM.2014.060165

LAM, J.S. L.; DAI, J. Environmental sustainability of logistics service provider: an ANP-QFD approach. The International Journal of Logistics Management, v. 26, n. 2, p. 313-333, 2015. http://dx.doi.org/10.1108/lJLM-08-2013-0088

LEE, J.H.; PHAAL, R.; LEE, S.-H. An integrated service-device-technology roadmap for smart city development. Technological Forecasting and Social Change, v. 80, n. 2, p. 286-306, 2013. http://dx.doi.org/10.1016/i.techfore.2012.09.020

LEE, Y.-C.; CHEN, J.-K. A new service development integrated model. The Service Industries Journal, v. 29, n. 12, p. 1669-1686, 2009.

http://dx.doi.org/10.1080/02642060902793573 
LI, H.; JI, Y., GU, X.; QI, G.; TANG, R. Module partition process model and method of integrated service product. Computers in Industry, v. 63, n. 4, p. 298-308, 2012. http://dx.doi.org/10.1016/j.compind.2012.02.015

LIANG, G.-S.; DING, J.-F.; PAN, C.-L. Applying fuzzy quality function deployment to evaluate solutions of the service quality for international port logistics centres in Taiwan. Proceedings of the Institution of Mechanical Engineers, Part M: Journal of Engineering for the Maritime Environment, v. 226, n. 4, p. 387-396, 2012.http://dx.doi.org/10.1177/1475090212443615

LIAO, C.-N.; KAO, H.-P. An evaluation approach to logistics service using fuzzy theory, quality function development and goal programming. Computers \& Industrial Engineering, v. 68, p. 54-64, 2014. http://dx.doi.org/10.1016/j.cie.2013.12.001

LIN, L.-Z.; HUANG, L.-C.; YEH, H.-R. Fuzzy group decision-making for service innovations in quality function deployment. Group Decision and Negotiation, v. 21, n. 4, p. 495-517, 2012. http://dx.doi.org/10.1007/s10726-010-9223-5

LIN, Y.; PEKKARINEN, S. QFD-based modular logistics service design. Journal of Business \& Industrial Marketing, v. 26, n. 5, p. 344-356, 2011.

http://dx.doi.org/10.1108/08858621111144406

LIU, H.-T. The extension of fuzzy QFD: From product planning to part deployment. Expert Systems with Applications, v. 36, n. 8, p. 11131-11144, 2009.

http://dx.doi.org/10.1016/j.eswa.2009.02.070

MAZUR, G. H. Voice of customer analysis: a modern system of front-end QFD tools, with case studies. In: ANNUAL QUALITY CONGRESS PROCEEDINGS-AMERICAN SOCIETY FOR QUALITY CONTROL. 1997. Anais.... p. 486-495.

MOTWANI, J.G.; SOWER, V. E.; KUMAR, A.; ANTONY, J.; DHAKAR, T.S. Integrating quality function deployment and benchmarking to achieve greater profitability.

Benchmarking: an International Journal, v. 13, n. 3, p. 290-310, 2006.

http://dx.doi.org/10.1108/14635770610668794

PARASURAMAN, A. Customer service in business-to-business markets: an agenda for research. Journal of Business \& Industrial Marketing, v. 13, n. 4/5, p. 309-321, 1998. http://dx.doi.org/10.1108/08858629810226636

STUART, F.I.; TAX, S.S. Planning for service quality: an integrative approach. International Journal of Service Industry Management, v. 7, n. 4, p. 58-77, 1996.

http://dx.doi.org/10.1108/09564239610129959

TORRACO, R.J. Writing integrative literature reviews: Guidelines and examples. Human resource development review, v. 4, n. 3, p. 356-367, 2005.

http://dx.doi.org/10.1177/1534484305278283

VALMORBIDA, S.M.I.; ENSSLIN, S.R.; ENSSLIN, L.; RIPOLL-FELIU, V.M. Avaliação de Desempenho para Auxílio na Gestão de Universidades Públicas: Análise da Literatura para Identificação de Oportunidades de Pesquisas. Contabilidade, Gestão e Governança, v. 17, n. 3, 2014.

WU, H-Y; LIN, H-Y. A hybrid approach to develop an analytical model for enhancing the service quality of e-learning. Computers \& Education, v. 58, n. 4, p. 1318-1338, 2012. http://dx.doi.org/10.1016/i.compedu.2011.12.025 
YEH, T-M. Determining medical service improvement priority by integrating the refined Kano model, Quality function deployment and Fuzzy integrals. African Journal of Business Management, v. 4, n. 12, p. 2534, 2010.

YEH, T-M; CHEN, S-H. Integrating refined Kano model, quality function deployment, and grey relational analysis to improve service quality of nursing homes. Human Factors and Ergonomics in Manufacturing \& Service Industries, v. 24, n. 2, p. 172-191, 2014. http://dx.doi.org/10.1002/hfm.20358

ZARE MEHRJERDI, Y. Quality function deployment and its profitability engagement: a systems thinking perspective. International Journal of Quality \& Reliability Management, v. 28, n. 9, p. 910-928, 2011. http://dx.doi.org/10.1108/02656711111172513

ZUO, W., HUANG, Q., FAN, C.; ZHANG, Z. Quality management of B2C e-commerce service based on human factors engineering. Electronic Commerce Research and Applications, v. 12, n. 5, p. 309-320, 2013. http://dx.doi.org/10.1016/j.elerap.2013.03.005

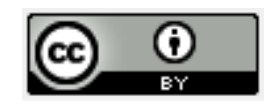

Artigo recebido em 11/07/2016 e aceito para publicação em 12/10/2016

DOI: http://dx.doi.org/10.14488/1676-1901.v17i1.2519 


\section{APÊNDICES}

\section{Apêndice 1}

Quadro A1.1 - Portfólio bibliográfico completo

\begin{tabular}{|c|c|c|c|c|}
\hline & Autores & Artigo & Periódico & SJR \\
\hline 1 & $\begin{array}{l}\text { Lam e Daí } \\
(2015)\end{array}$ & $\begin{array}{l}\text { Developing supply chain security design of } \\
\text { logistics service providers }\end{array}$ & $\begin{array}{l}\text { International Journal } \\
\text { of Physical } \\
\text { Distribution \& } \\
\text { Logistics } \\
\text { Management }\end{array}$ & 1,930 \\
\hline 2 & $\begin{array}{l}\text { Liao e Kao } \\
(2014)\end{array}$ & $\begin{array}{l}\text { An evaluation approach to logistics service } \\
\text { using fuzzy theory, quality function development } \\
\text { and goal programming }\end{array}$ & $\begin{array}{l}\text { Computers \& } \\
\text { Industrial } \\
\text { Engineering }\end{array}$ & 1,712 \\
\hline 3 & $\begin{array}{l}\text { Chen, } \\
\text { Hsu, Hsu e } \\
\text { Lee (2014) }\end{array}$ & $\begin{array}{l}\text { Ensuring the quality of e-shopping specialty } \\
\text { foods through efficient logistics service }\end{array}$ & $\begin{array}{l}\text { Trends in Food } \\
\text { Science \& } \\
\text { Technology }\end{array}$ & 1,824 \\
\hline 4 & $\begin{array}{l}\text { Yeh e } \\
\text { Chen } \\
(2014)\end{array}$ & $\begin{array}{l}\text { Integrating Refined Kano Model, Quality } \\
\text { Function Deployment, and Grey Relational } \\
\text { Analysis to Improve Service Quality of Nursing } \\
\text { Homes }\end{array}$ & $\begin{array}{l}\text { Human Factors and } \\
\text { Ergonomics in } \\
\text { Manufacturing \& } \\
\text { Service Industries }\end{array}$ & 0,213 \\
\hline 5 & $\begin{array}{l}\text { Lee, Phaal } \\
\text { e Lee } \\
\text { (2013) }\end{array}$ & $\begin{array}{l}\text { An integrated service-device-technology } \\
\text { roadmap for smart city development }\end{array}$ & $\begin{array}{l}\text { Technological } \\
\text { Forecasting and } \\
\text { Social Change }\end{array}$ & 1,310 \\
\hline 6 & $\begin{array}{l}\text { Hsu } \\
(2013)\end{array}$ & $\begin{array}{l}\text { Improving the service operations of container } \\
\text { terminals }\end{array}$ & $\begin{array}{l}\text { International Journal } \\
\text { of Logistics } \\
\text { Management }\end{array}$ & $\begin{array}{l}\text { SEM } \\
\text { SJR }\end{array}$ \\
\hline 7 & $\begin{array}{l}\text { Zuo, } \\
\text { Huang, } \\
\text { Fan e } \\
\text { Zhang } \\
(2013)\end{array}$ & $\begin{array}{l}\text { Quality management of B2C e-commerce } \\
\text { service based on human factors engineering }\end{array}$ & $\begin{array}{l}\text { Electronic } \\
\text { Commerce } \\
\text { Research and } \\
\text { Applications }\end{array}$ & 1,065 \\
\hline 8 & $\begin{array}{l}\text { Wu e Lin } \\
(2012)\end{array}$ & $\begin{array}{l}\text { A hybrid approach to develop an analytical } \\
\text { model for enhancing the service quality of e- } \\
\text { learning }\end{array}$ & $\begin{array}{l}\text { Computers \& } \\
\text { Education }\end{array}$ & 2,608 \\
\hline 9 & $\begin{array}{l}\text { Liang, } \\
\text { Ding e Pan } \\
\text { (2012) }\end{array}$ & $\begin{array}{l}\text { Applying fuzzy quality function deployment to } \\
\text { evaluate solutions of the service quality for } \\
\text { international port logistics centres in Taiwan }\end{array}$ & $\begin{array}{l}\text { Journal of } \\
\text { Engineering for the } \\
\text { Maritime } \\
\text { Environment }\end{array}$ & 0,615 \\
\hline 10 & $\begin{array}{l}\text { Kim e } \\
\text { Yoon } \\
(2012)\end{array}$ & $\begin{array}{l}\text { Developing a process of concept generation for } \\
\text { new product-service systems: a QFD and TRIZ- } \\
\text { based approach }\end{array}$ & Service Business & 0,371 \\
\hline 11 & $\begin{array}{l}\text { Lin, Huang } \\
\text { e Yeh } \\
(2012)\end{array}$ & $\begin{array}{l}\text { Fuzzy Group Decision-Making for Service } \\
\text { Innovations in Quality Function Deployment }\end{array}$ & $\begin{array}{l}\text { Group Decision and } \\
\text { Negotiation }\end{array}$ & 0,439 \\
\hline 12 & $\begin{array}{l}\text { Geum, } \\
\text { Kwak e } \\
\text { Park } \\
\text { (2012) }\end{array}$ & $\begin{array}{l}\text { Modularizing services: A modified HoQ } \\
\text { approach }\end{array}$ & $\begin{array}{l}\text { Computers \& } \\
\text { Industrial } \\
\text { Engineering }\end{array}$ & 1,712 \\
\hline 13 & $\begin{array}{l}\mathrm{Li}, \mathrm{Ji}, \mathrm{Cu}, \\
\text { Qi e Tang } \\
(2012)\end{array}$ & $\begin{array}{l}\text { Module partition process model and method of } \\
\text { integrated service product }\end{array}$ & $\begin{array}{l}\text { Computers in } \\
\text { Industry }\end{array}$ & 1,345 \\
\hline
\end{tabular}




\begin{tabular}{|c|c|c|c|c|}
\hline 14 & $\begin{array}{l}\text { Dror e } \\
\text { Sukenik } \\
\text { (2011) }\end{array}$ & A strategic service quality framework using QFD & $\begin{array}{l}\text { Total Quality } \\
\text { Management \& } \\
\text { Business Excellence }\end{array}$ & 0,512 \\
\hline 15 & $\begin{array}{l}\text { Geng, } \\
\text { Chu, Xue e } \\
\text { Zhang } \\
(2011)\end{array}$ & $\begin{array}{l}\text { A systematic decision-making approach for the } \\
\text { optimal product-service system planning }\end{array}$ & $\begin{array}{l}\text { Expert Systems with } \\
\text { Applications }\end{array}$ & 1,358 \\
\hline 16 & $\begin{array}{l}\text { Chen e } \\
\text { Chou } \\
\text { (2011) }\end{array}$ & $\begin{array}{l}\text { Applying GRA and QFD to Improve Library } \\
\text { Service Quality }\end{array}$ & $\begin{array}{l}\text { Journal of Academic } \\
\text { Librarianship }\end{array}$ & 1,533 \\
\hline 17 & $\begin{array}{l}\text { Kuo, Wu, } \\
\text { Hsu e } \\
\text { Chen } \\
(2011)\end{array}$ & $\begin{array}{l}\text { Improving outpatient services for elderly patients } \\
\text { in Taiwan: A qualitative study }\end{array}$ & $\begin{array}{l}\text { Archives of } \\
\text { Gerontology and } \\
\text { Geriatrics }\end{array}$ & 0,583 \\
\hline 18 & $\begin{array}{l}\text { Lin e } \\
\text { Pekkarinen } \\
(2011)\end{array}$ & QFD-based modular logistics service design & $\begin{array}{l}\text { Journal of Business } \\
\text { \& Industrial } \\
\text { Marketing }\end{array}$ & 0,710 \\
\hline 19 & $\begin{array}{l}\text { Jeaghi, } \\
\text { Amiri e } \\
\text { Mollaee } \\
(2010)\end{array}$ & $\begin{array}{l}\text { A quality function deployment approach to HR } \\
\text { strategy formation and prioritization: Meeting } \\
\text { client satisfaction in service organizations }\end{array}$ & $\begin{array}{l}\text { African Journal of } \\
\text { Business } \\
\text { Management }\end{array}$ & $\begin{array}{l}\text { SEM } \\
\text { SJR }\end{array}$ \\
\hline 20 & $\begin{array}{l}\text { Yeh } \\
(2010)\end{array}$ & $\begin{array}{l}\text { Determining medical service improvement } \\
\text { priority by integrating the refined Kano model, } \\
\text { Quality function deployment and Fuzzy integrals }\end{array}$ & $\begin{array}{l}\text { African Journal of } \\
\text { Business } \\
\text { Management }\end{array}$ & $\begin{array}{l}\text { SEM } \\
\text { SJR }\end{array}$ \\
\hline 21 & $\begin{array}{l}\text { Garibay, } \\
\text { Gutierrez e } \\
\text { Figueroa } \\
(2010)\end{array}$ & $\begin{array}{l}\text { Evaluation of a Digital Library by Means of } \\
\text { Quality Function Deployment (QFD) and the } \\
\text { Kano Model }\end{array}$ & $\begin{array}{l}\text { Journal of Academic } \\
\text { Librarianship }\end{array}$ & 1,533 \\
\hline 22 & $\begin{array}{l}\text { Lee e } \\
\text { Chen } \\
(2009) \\
\end{array}$ & A new service development integrated model & $\begin{array}{l}\text { Service Industries } \\
\text { Journal }\end{array}$ & 0,327 \\
\hline 23 & $\begin{array}{l}\text { Ding } \\
(2009)\end{array}$ & $\begin{array}{l}\text { Applying fuzzy quality function deployment } \\
\text { (QFD) to identify solutions of service delivery } \\
\text { system for port of Kaohsiung }\end{array}$ & Quality \& Quantity & 0,465 \\
\hline 24 & $\begin{array}{l}\text { An, Lee e } \\
\text { Park } \\
(2008)\end{array}$ & $\begin{array}{l}\text { Development of an integrated product-service } \\
\text { roadmap with QFD A case study on mobile } \\
\text { communications }\end{array}$ & $\begin{array}{l}\text { International Journal } \\
\text { of Service Industry } \\
\text { Management }\end{array}$ & $\begin{array}{l}\text { SEM } \\
\text { SJR }\end{array}$ \\
\hline 25 & $\begin{array}{l}\text { Daniels e } \\
\text { Seler } \\
(2008)\end{array}$ & $\begin{array}{l}\text { Use of quality management methods in the } \\
\text { transition from efficacious prevention programs } \\
\text { to effective prevention services }\end{array}$ & $\begin{array}{l}\text { American Journal of } \\
\text { Community } \\
\text { Psychology }\end{array}$ & 0,947 \\
\hline
\end{tabular}

Fonte: elaborado pelos autores baseado na busca e organização bibliográfica 
APÊNDICE 2 - Quadro A2.1 - Análise dos artigos quanto a objetivos gerais, setor da economia e metodologias

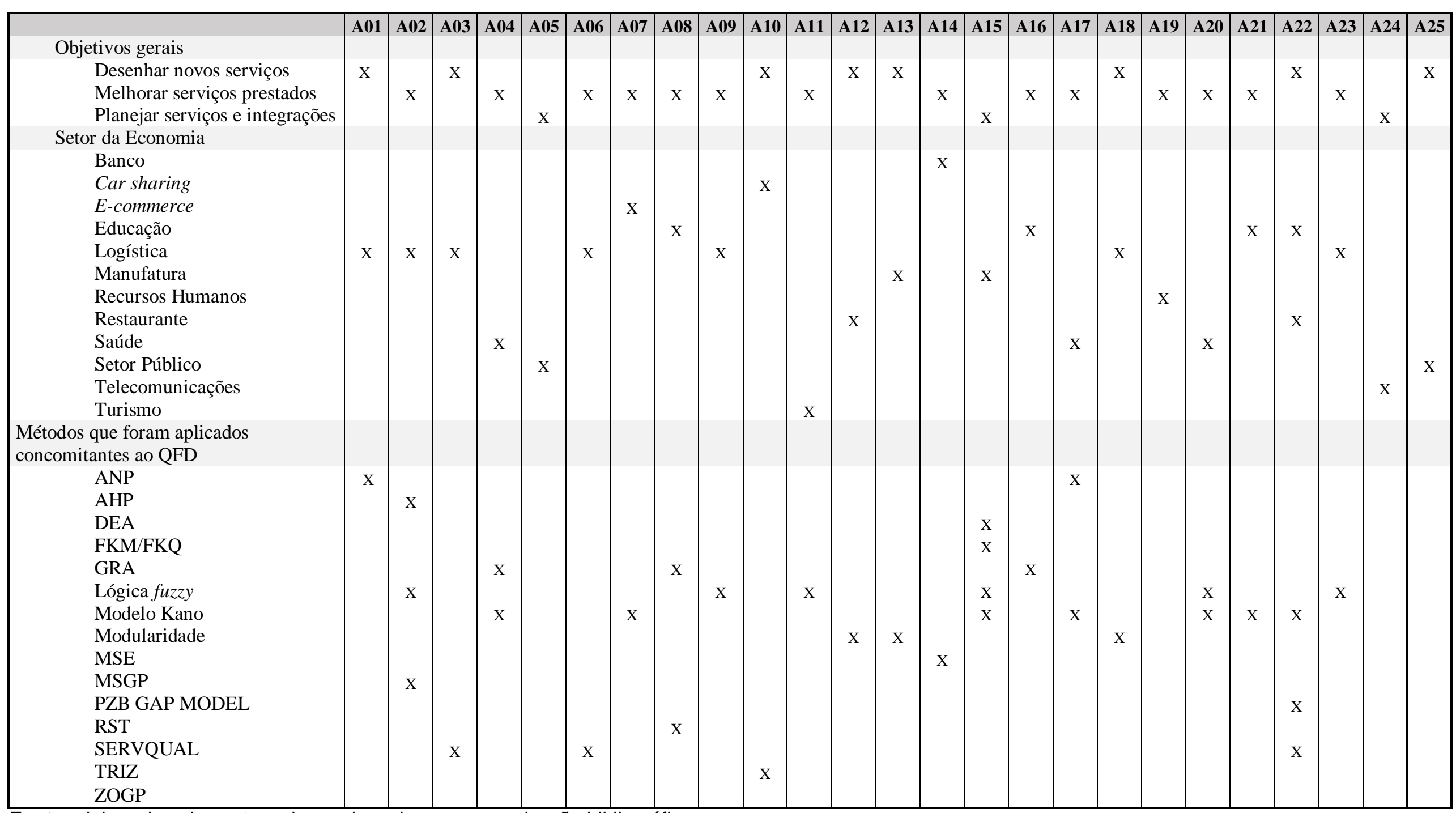

Fonte: elaborado pelos autores baseado na busca e organização bibliográfica 